\title{
The Practice of 'Othering' during COVID-19 Pandemic in Malaysia: From the cities to the highlands
}

\author{
Poline Bala ${ }^{1}$ and Linda A. Lumayag ${ }^{2}$
}

\begin{abstract}
This paper attempts to throw light on the concept of 'othering' previously framed through the prism of identity politics. As COVID-19 continues to ravage our economy and social life, we turn to looking at two contested sites of the highland national borders and the urban cities to understand how the 'othering' idea manifests itself right when the pandemic began in late December 2019. The first situation is described in social media as Malaysia's mass rage and xenophobic rants against Rohingya refugees and the second scenario is the closure of international borders between Sarawak and East Kalimantan in the uplands located in the northeast of Central Borneo. By analysing texts in the form of narratives, anecdotes and communication encountered through social media, the paper raised questions whether these were manifestations of specific forms of marginalisation of people based on perceived group differences or simply expressions of fear of COVID-19 disease and anxiety about scarcity of resources as a result of the pandemic.
\end{abstract}

Keywords: 'othering'; COVID-19; xenophobia; Robingy a communities; pandemic; migration; border communities

\section{Introduction}

The global pandemic currently embodied by COVID-19 infections continues to wreak havoc in our economy, lifestyles, social interaction and political governance (Sirkeci and Cohen, 2020). More than a year since COVID-19 came to ravage human lives, it is clearly shaping the contours of our new everyday practices across countries from the movement restrictions to health protocols. At the same time, however, countries behave and respond differently to the pandemic. These responses at the national and international level vary from providing immediate relief care packages in the form of food aid and cash, moratorium of monthly loan payments and rentals, suspension of the physical school-based learning, and closing of the national borders, for example. One obvious, although less well articulated at the national level of countries, is the crystallisation of social inequality that is simmering despite the popular belief of economic growth in certain industries such as in the digital technology and communication, online food services and others, as a consequence of the different policies, strategies and policy actions, persistence of negative 'othering' attitudes and practices. One of the simmering manifestations of social inequality is the practice of wedging divisions based on citizenship, ethnicity/race, gender, geographical location, and class made more glaring in this time of pandemic.

\footnotetext{
${ }^{1}$ Poline Bala, PhD. Director, Institute of Borneo Studies, Universiti Malaysia Sarawak 94300 Kota Samarahan, Sarawak, Malaysia. Email: bpoline@unimas.my.

${ }^{2}$ Linda A. Lumayag, PhD. (corresponding author) Programme Coordinator and Senior Lecturer, Politics and Government Studies, Faculty of Social Sciences \& Humanities, Universiti Malaysia Sarawak 94300 Kota Samarahan, Sarawak, Malaysia.

Email: allinda@unimas.my.
} 